\title{
Characterization of the mrgRS locus of the opportunistic pathogen Burkholderia pseudomallei: temperature regulates the expression of a two-component signal transduction system Magdy E Mahfouz ${ }^{1}$, T Hilton Grayson*2, David AB Dance ${ }^{3}$ and Martyn L Gilpin²
}

Address: ${ }^{1}$ Department of Biological and Geological Sciences, Faculty of Education, Kafr ElSheikh, Tanta University, Egypt, ${ }^{2}$ School of Biological Sciences, University of Plymouth, England, UK and ${ }^{3}$ Health Protection Agency South West, Derriford, Plymouth, England, UK

Email: Magdy E Mahfouz - mmahfouz4@yahoo.co.uk; T Hilton Grayson* - thomas.grayson@plymouth.ac.uk;

David AB Dance - david.dance@phnt.swest.nhs.uk; Martyn L Gilpin - m.gilpin@plymouth.ac.uk

* Corresponding author

Published: 07 August 2006

BMC Microbiology 2006, 6:70 doi:10.1186/1471-2180-6-70

This article is available from: http://www.biomedcentral.com/I47I-2180/6/70

(c) 2006 Mahfouz et al; licensee BioMed Central Ltd.

This is an Open Access article distributed under the terms of the Creative Commons Attribution License (http://creativecommons.org/licenses/by/2.0), which permits unrestricted use, distribution, and reproduction in any medium, provided the original work is properly cited.

\begin{abstract}
Background: Burkholderia pseudomallei is a saprophyte in tropical environments and an opportunistic human pathogen. This versatility requires a sensing mechanism that allows the bacterium to respond rapidly to altered environmental conditions. We characterized a twocomponent signal transduction locus from B. pseudomallei 204, $\mathrm{mrgR}$ and $\mathrm{mrgS}$, encoding products with extensive homology with response regulators and histidine protein kinases of Escherichia coli, Bordetella pertussis, and Vibrio cholerae.
\end{abstract}

Results: The locus was present and expressed in a variety of $B$. pseudomallei human and environmental isolates but was absent from other Burkholderia species, $B$. cepacia, $B$. cocovenenans, B. plantarii, B. thailandensis, B. vandii, and B. vietnamiensis. A 2128 bp sequence, including the full response regulator $m r g R$, but not the sensor kinase $m r g S$, was present in the $B$. mallei genome. Restriction fragment length polymorphism downstream from mrgRS showed two distinct groups were present among $B$. pseudomallei isolates. Our analysis of the open reading frames in this region of the genome revealed that transposase and bacteriophage activity may help explain this variation. MrgR and MrgS proteins were expressed in B. pseudomallei 204 cultured at different $\mathrm{pH}$, salinity and temperatures and the expression was substantially reduced at $25^{\circ} \mathrm{C}$ compared with $37^{\circ} \mathrm{C}$ or $42^{\circ} \mathrm{C}$ but was mostly unaffected by $\mathrm{pH}$ or salinity, although at $25^{\circ} \mathrm{C}$ and $0.15 \% \mathrm{NaCl}$ a small increase in MrgR expression was observed at $\mathrm{pH}$ 5. MrgR was recognized by antibodies in convalescent sera pooled from melioidosis patients.

Conclusion: The results suggest that mrgRS regulates an adaptive response to temperature that may be essential for pathogenesis, particularly during the initial phases of infection. B. pseudomallei and $B$. mallei are very closely related species that differ in their capacity to adapt to changing environmental conditions. Modifications in this region of the genome may assist our understanding of the reasons for this difference. 


\section{Background}

The saprophyte Burkholderia pseudomallei is an opportunistic pathogen that is capable of intracellular survival [1,2] and causes melioidosis, a frequently fatal disease of humans and animals, which can be difficult to diagnose [3]. Although the pathogen is mainly distributed in the soil and water of tropical regions, especially south-east Asia and northern Australia, it is highly adaptable, nutritionally versatile and able to survive and grow in a wide range of environments [4-8]. The disease encompasses a broad spectrum of clinical symptoms and outcomes, including long periods of latency up to 62 years [9], and affects the lives of many millions of people [10].

The pathogenesis of $B$. pseudomallei infections involves the expression of cell-associated components such as lipopolysaccharide, pili, extracellular polysaccharide, and flagella [3] as well as secreted factors including toxins [11], protease [12], siderophore [13] and phospholipase [14]. Although capsular polysaccharide has been shown to enhance the intracellular survival and virulence of the pathogen, the role of this and other factors in pathogenicity and host resistance has not been conclusively resolved [15-17]. It is possible that pathogenesis involves the expression of many genes that are regulated in response to complex environmental signals.

Many bacterial pathogens possess signal transduction systems that are able to elicit adaptive responses to environmental variations and consequently have an important role in regulating the expression of genes that are crucial for survival and infection [18]. The prevalence of twocomponent transduction systems in a wide variety of bacterial species has stimulated interest and some limited success in designing new classes of broad-spectrum antimicrobials that can block these signalling pathways $[19,20]$. The most attractive reason for targeting these systems, such as PhoP/PhoQ from Salmonella typhimurium and BvgA/BvgS from Bordetella pertussis, is that they control the expression of genes required for infectivity and virulence in pathogenic bacteria [21]. Bacterial twocomponent systems are typically composed of a transmembrane histidine protein kinase that serves as an environmental sensor and a cytoplasmic response regulator that uses reversible phosphorylation to regulate gene expression in response to changing environmental conditions $[22,23]$.

Most, if not all, bacteria can respond and adapt to changes in environmental conditions, such as temperature, osmotic pressure and $\mathrm{pH}$, by regulating gene expression $[24,25]$. Understanding how these conditions affect the expression of genes which can regulate an adaptive response is important for improving our understanding of opportunistic pathogens, such as B. pseudomallei, that are able to survive a wide range of environmental variations. In this study we report the identification of a two-component signal transduction system from B. pseudomallei encoding proteins most similar in structure to RcsB and $\mathrm{RcsC}$ that regulate capsule synthesis in Escherichia coli. We cloned and characterized the genes and examined their expression under conditions that $B$. pseudomallei may encounter during its life cycle. In order to more fully characterize this region of the $B$. pseudomallei genome we examined genetic variation downstream from the $m r g R S$ locus in a variety of $B$. pseudomallei isolates and show that 2 distinct groups of isolates can be distinguished.

\section{Results and discussion Identification of genes encoding a two-component signal transduction system}

A DNA sequence from the coding region of a two-component regulatory gene was amplified by PCR from $B$. pseudomallei 204 chromosomal DNA, subcloned into pUC18, sequenced on both strands to confirm the identity, labelled and used to probe $B$. pseudomallei $\lambda$ ZAP and $\lambda$ GEM-11 genomic DNA libraries. A $\lambda$ GT-11 genomic library constructed from B. pseudomallei strain 204 by Dr C. Davies, University of Plymouth was also screened. Approximately 4000, 5000 and 8000 recombinant phage plaques were screened from which 5,3 , and 2 positive plaques were isolated from the $\lambda$ GEM-11, $\lambda$ ZAP Express, and $\lambda$ GT-11 libraries, respectively. Each was found to contain identical sequence information in the regions of overlap (Figure 1). This work was initiated and completed well before the $B$. pseudomallei genome sequence was published, and was not based on any genome sequence information.

Of the two open reading frames (ORFs) identified, one (666 bp) designated $m r g R$ for melioidosis agent regulatory gene regulator, possesses a promoter but lacks an obvious transcriptional termination sequence after the stop codon. The translated product $(23,860 \mathrm{Da})$ shares extensive similarity with a large family of response regulators, particularly the RcsB proteins of Erwinia amylovora, E. coli, and Salmonella typhi, and BvgA of Bordetella pertussis (28-31\% identity). A helix-turn-helix DNA binding domain is located in the C-terminal portion (residues 158-215) which is a common feature of response regulators of the LuxR/FixJ family of cytoplasmic transcriptional regulators. In addition, the protein possesses conserved residues that characterize this family, including Asp-61 which is believed to be phosphorylated, and Asp-15, Asp16, Thr-191, and Lys-202, which are believed to contribute to the acidic pocket for the phosphorylation site $[18,26]$. These features strongly suggest that MrgR should be assigned to the LuxR/FixJ family of transcriptional regulators that are located in the cytoplasm and are thought 


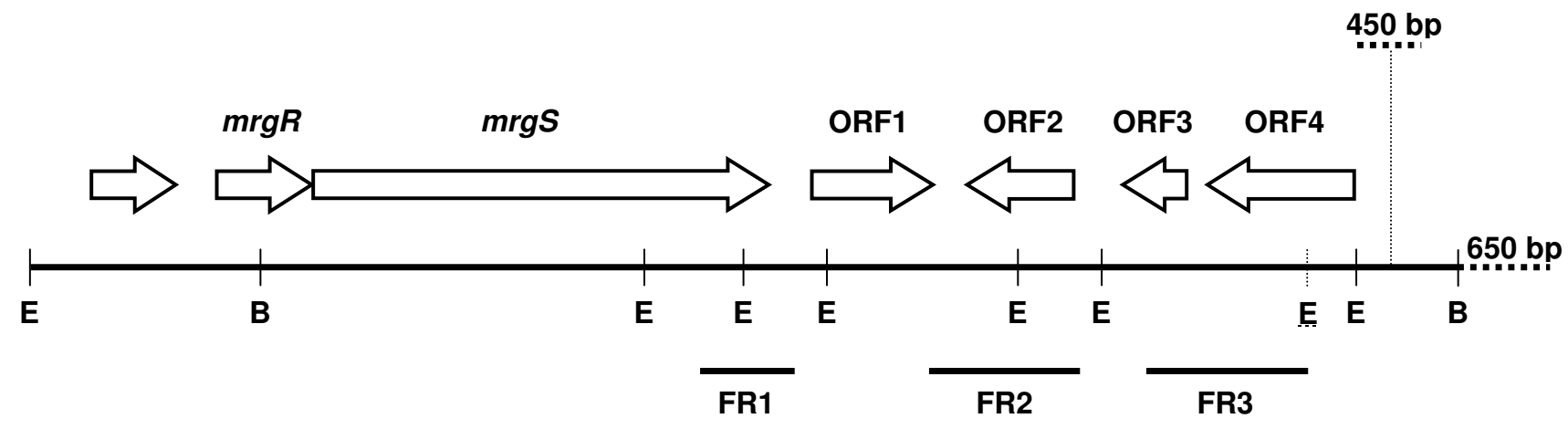

$1 \mathrm{~kb}$

Figure I

Map of the mrgRS locus of the B. pseudomallei genome (GenBank accession no. DQ4I8486). Open reading frames and direction of transcription are marked (arrows). See text for details of $m r g R$ and $m r g S$, ORFs I-4, and oligonucleotide probes FRI-3. E = EcoRI site, $B=B c l l$ site. The positions of the additional EcoRI site that is described in the text and which is present in many $B$. pseudomallei isolates, and the $450 \mathrm{bp}$ bacteriophage-like insertion and $650 \mathrm{bp}$ transposase-like sequence that accompany this extra restriction site, are indicated by dotted lines.

to bind to specific promoter sequences upstream of regulated genes.

The second ORF (3237 bp) was designated mrgS for melioidosis agent regulatory gene sensor and is transcribed in the same direction as $m r g R$. The initiation codon of $m r g S$ overlaps by a single nucleotide with the termination codon of $m r g R$ i.e. TGATG. This feature has been described for genes encoding two-component regulator systems from different bacterial species such as ompR/envZ of E. coli [27] and irlRS operon of B. pseudomallei [28]. Eight nucleotides upstream from the ATG start codon and in the distal portion of $m r g R$, there is a potential S-D sequence (AAGGA) and 17 bp downstream from the stop codon lies a 36 bp GC-rich inverted repeat $(\Delta G=-26 \mathrm{kcal})$ which could act as a strong transcriptional terminator for $m r g S$. The absence of secondary structure around the stop codon of $m r g R$ suggests that transcription does not terminate at that point and the lack of an obvious promoter region for $m r g S$ suggests that transcription may be controlled from the $\operatorname{mrgR}$ promoter and that both ORFs are transcribed as a polycistronic unit.

The translated product of $\operatorname{mrgS}(118,267 \mathrm{Da})$ shares homology with a family of two-component histidine kinases that function by sensing environmental stimuli, particularly RcsC of E. coli and also sensor kinases of $S$. typhi and Vibrio cholerae (18-22\% identity). RcsC is the sensor regulator of capsule synthesis in E. coli and many other species, including E. amylovora, $P$. mirabilis and $S$. typhi [29]. MrgS possesses many of the features common to this family of sensor proteins including two strongly hydrophobic transmembrane sequences located in the Nterminal portion of the protein between residues 29-49 and 322-342, and five blocks of conserved functional subdomains located in the C-terminal portion of the protein including His-503 that is the proposed site of phosphorylation, and the $\mathrm{N}, \mathrm{G}_{1}$ (DTGVG), F, and $\mathrm{G}_{2}$ (GTGLG) boxes at positions 620, 647-651, 661 and 677-681, respectively [30]. These motifs are presumed to form a nucleotide-binding surface within the active site of the molecule. In addition, several conserved Asp residues are present in MrgS, at positions 860, 898, 903, 910 and 949, and may contribute to the additional response regulator domain that is a characteristic of hybrid histidine kinases [31]. Like BvgS of B. pertussis, MrgS is a member of a family of complex sensor proteins, the hybrid kinases, which contain multiple cytoplasmic domains that are believed to participate in a phosphorylation cascade in signal transduction. The presence of two hydrophobic transmembrane domains separated by a large loop of 273 amino acids which may act as a periplasmic environmental monitor is appropriate for a sensor protein that lends itself to signal transduction [18].

Because the deduced amino acid sequences of $m r g R$ and $m r g S$ are most similar to the sequences of genes encoding known response regulators and sensors, it has been inferred that these two genes constitute a two-component signal transduction system. Since the completion of our work the B. pseudomallei genome sequence has been published [32] and $m r g R$ and $m r g S$ are now known to corre- 
spond to locus tags BPSL1633 and BPSL1634, respectively, in the genome sequence of $B$. pseudomallei K96243.

\section{The mrgRS locus is present in B. pseudomallei but not other Burkholderia species}

Southern hybridization analysis of genomic DNA extracted from 19 isolates of B. pseudomallei derived from environmental and clinical samples from different areas of the world (Table 1), showed that all of the isolates possessed a single EcoRI fragment of $\sim 4.3 \mathrm{~kb}$ in size (Figure 2a) corresponding to the EcoRI fragment spanning most of the $m r g R S$ locus. The locus was not detected in genomic DNA from E. coli, Pseudomonas aeruginosa, Pseudomonas fluorescens, or other Burkholderia species including the closely related Burkholderia thailandensis (Figure 2b). We compared the mrgRS locus from B. pseudomallei 204 with the completed genome sequences for B. pseudomallei isolates K96243 and $1710 \mathrm{~b}$ and with the unfinished sequences of a further 8 strains that are available on GenBank and found that there is some variation amongst the different strains within this region of the genome. Although the $\operatorname{mrg} R$ reading frame is preserved there are modifications within the 5 ' region upstream from the $m r g R$ start codon that may have implications for the expression of the gene. In some strains there are also modifications within the coding region of $\mathrm{mrgS}$, including a single nucleotide addition (nt 3051) that changes the reading frame and adds 4 additional amino acids to the last 61 residues of the $\mathrm{C}$-terminus of $\mathrm{MrgS}$ and which may have functional consequences. A search of the genome sequences of 8 strains of the obligate pathogen Burkholderia mallei which are available on GenBank, revealed that 2128 bp encompassing the entire $m r g R$ gene sequence and including 1319 bp upstream of the $m r g R$ start codon, is highly conserved in 4 of the 8 strains of this organism (98\% identity over $2128 \mathrm{bp}$ ). The full $\mathrm{mrgR}$ gene sequence shares $100 \%$ identity with B. mallei. Apart from the initial 144 bp downstream from the start codon, the $m r g S$ sequence is absent from $B$. mallei and this feature may contribute to its inability to adapt to conditions outside a suitable host, in contrast with B. pseudomallei $[33,34]$.

\section{MrgR and MrgS are present in B. pseudomallei cell lysates but not culture supernatant}

Strains of $B$. pseudomallei representing isolates from clinical $(112,204,576)$ and environmental (E8, 98, 216) samples were cultured at $37^{\circ} \mathrm{C}$ and whole cell lysates and concentrated culture supernatants were prepared, proteins were separated by SDS-PAGE, transferred to nitrocellulose and probed with antibodies recognising MrgR and MrgS. Anti-MrgR and anti-MrgS each recognized more than one band on Western blots of whole cell lysates of all strains. In all strains, anti-MrgR recognized 3 major bands close to the expected size of MrgR, 24-28 kDa, as well as a strong band of $\sim 80 \mathrm{kDa}$ (Figure 3). Members of the response regulator protein family are known to be phosphorylated at specific residues [26] and because MrgR possesses the same features as these proteins we propose that the 24-28 $\mathrm{kDa}$ bands may represent different phosphorylation states of the MrgR protein. In some strains, bands of 90 and/or 150 kDa were faintly visible. Anti-MrgS strongly stained a band of $\sim 115 \mathrm{kDa}$, close to the predicted size of MrgS, and another band of $\sim 30 \mathrm{kDa}$ (Figure 4). In some strains a band of 90-100 kDa was also visible. Preincubating anti-MrgR and anti-MrgS with their cognate immunising peptide, as described in the antibody specificity data supplement (see Additional file 1), abolished all staining. Hence additional bands possess the same epitope and may represent either breakdown products of the $118 \mathrm{kDa}$ MrgS protein or, in the case of MrgR, an additional antigenically-related $80 \mathrm{kDa}$ protein. MrgR and MrgS were not detected in concentrated broth culture supernatant (result not shown) supporting the suggestion that MrgR and MrgS are not secreted proteins.

\section{Convalescent sera from melioidosis patients reacts with MrgR}

Western blots of whole cell lysates from 6 isolates of $B$. pseudomallei that were probed with convalescent sera pooled from 6 melioidosis patients (supplied by Vanaporn Wuthiekanun, Wellcome Trust-Oxford UniversityMahidol University Tropical Medicine Research Programme, Bangkok, Thailand) demonstrated strong antibody recognition of multiple components in all isolates (see Additional file 4). Furthermore, Western blots of cell lysates of E. coli expressing MBP-MrgR that were probed with the same sera stained a band of $\sim 60 \mathrm{kDa}$ that was present in soluble, insoluble, and amylose resin purified extracts from bacteria that had been induced with IPTG (Figure 5). A low level of recognition was evident in uninduced cell extracts, similar to that observed when Western blots of the same cell extracts were probed with anti-MrgR. The convalescent sera did not recognize purified MBP, MBP-MrgS or any other E. coli components and no recognition of MBP-MrgR was seen when Western blots of the same extracts were probed with serum from an individual not previously exposed to $B$. pseudomallei (data not shown). This raises the possibility that MrgR may be expressed by B. pseudomallei during melioidosis infection although it is unclear how a regulatory protein that is not apparently secreted in vitro would be exposed to the host immune system and the presence of cross reactive epitopes on related proteins can not be excluded.

\section{Expression of MrgR and MrgS proteins under different growth conditions}

B. pseudomallei 204, from which the mrgRS locus was cloned and characterized, was cultured under a variety of different conditions. A range of temperatures, $\mathrm{pH}$ and 
Table I: Bacterial strains used in this study

\begin{tabular}{|c|c|c|c|c|c|}
\hline Strain & Strain origin & Sample & Geographical origin & Date & Source \\
\hline \multicolumn{6}{|l|}{ Burkholderia pseudomallei } \\
\hline E8 & Environment & Soil & NE Thailand & 1990 & 1 \\
\hline 19 & Environment & Soil & Singapore & 1991 & 1 \\
\hline 22 & Environment & Soil & Burkina Faso & 1973 & 2 \\
\hline 25 & Environment & Soil & Madagascar & 1977 & I \\
\hline E25 & Environment & Soil & Thailand & - & 1 \\
\hline 33 & Environment & Manure & France & 1976 & 1 \\
\hline 46 & Human & Blood & NE Thailand & 1988 & 1 \\
\hline 53 & Human & Urine & NE Thailand & 1987 & 1 \\
\hline 97 & Environment & Soil & Australia & - & I \\
\hline 98 & Environment & Soil & Australia & - & 1 \\
\hline 102 & Environment & Soil & Australia & - & 1 \\
\hline 112 & Human & Multiple & NE Thailand & 1992 & 1 \\
\hline 204 & Human & Blood & Thailand & - & 1 \\
\hline 212 & Environment & Soil & NE Thailand & 1990 & I \\
\hline 216 & Environment & Soil & NE Thailand & 1990 & I \\
\hline 217 & Environment & Soil (wet) & NE Thailand & 1990 & 1 \\
\hline 392 & Human & Pus & NE Thailand & 1989 & I \\
\hline 426 & Environment & Soil & Vietnam & - & 1 \\
\hline 448 & Environment & Soil & Vietnam & - & 1 \\
\hline 576 & Human & Blood & Thailand & - & I \\
\hline Hainan I (HI) & Human & Abscess & China & 1996 & 2 \\
\hline Hainan 2D (H2D) & Human & Abscess & China & 1996 & 2 \\
\hline Hainan 55 (H55) & Human & Abscess & China & 1996 & 2 \\
\hline Hainan 706 (H706) & Human & Abscess & China & 1996 & 2 \\
\hline \multicolumn{6}{|l|}{ Burkholderia thailandensis } \\
\hline E27 & Environment & Soil & Thailand & - & 2 \\
\hline E38 & Environment & Soil & Thailand & - & 2 \\
\hline E82 & Environment & Soil & NE Thailand & 1990 & 2 \\
\hline E255 & Environment & Soil & NE Thailand & - & 2 \\
\hline E256 & Environment & Soil & Thailand & - & 2 \\
\hline E260 & Environment & Soil & Central Thailand & 1993 & 2 \\
\hline \multicolumn{6}{|l|}{ Other Burkholderia species } \\
\hline B. cocovenenans LMGII626 & & & & & 2 \\
\hline B. plantarii LMG 10908 & & & & & 2 \\
\hline B. vietnamiensis LMG6998 & & & & & 2 \\
\hline B. cepacia Illa non-epidemic & & & & & 2 \\
\hline B. vandii LMGI0620 & & & & & 2 \\
\hline \multicolumn{6}{|l|}{ Other species } \\
\hline Pseudomonas aeruginosa & & & & & 3 \\
\hline Pseudomonas fluorescens & & & & & 3 \\
\hline Escherichia coli DH5 $\alpha$ & & & & & 3 \\
\hline
\end{tabular}

I: David Dance HPA South West, Derriford, Plymouth; 2: Ty Pitt, Centre for Infections, HPA, Colindale, London; 3: University of Plymouth culture collection

salinities were chosen to reflect a variety of natural and host environments to which $B$. pseudomallei might be exposed within the tropics [6]. Although B. pseudomallei can grow over a wide range of variation in these parameters, we obtained the highest yields of protein at $42^{\circ} \mathrm{C}, \mathrm{pH}$ 6.8 and $0.5 \% \mathrm{NaCl}$. Substantial yields of protein were also obtained at either 37 or $42^{\circ} \mathrm{C}$, pH 5 and $0.15 \% \mathrm{NaCl}$, and the lowest yields were recorded at $\mathrm{pH}$ 8. These observations support in vitro and in vivo studies showing that $B$. pseudomallei readily adapts to acidic environments $[7,35,36]$ and has an optimum growth temperature in vitro of $37-42^{\circ} \mathrm{C}[6]$. Birds are considered to be relatively resistant to $B$. pseudomallei infection [37] but the strong growth at $42^{\circ} \mathrm{C}$ of all of the isolates of $B$. pseudomallei 

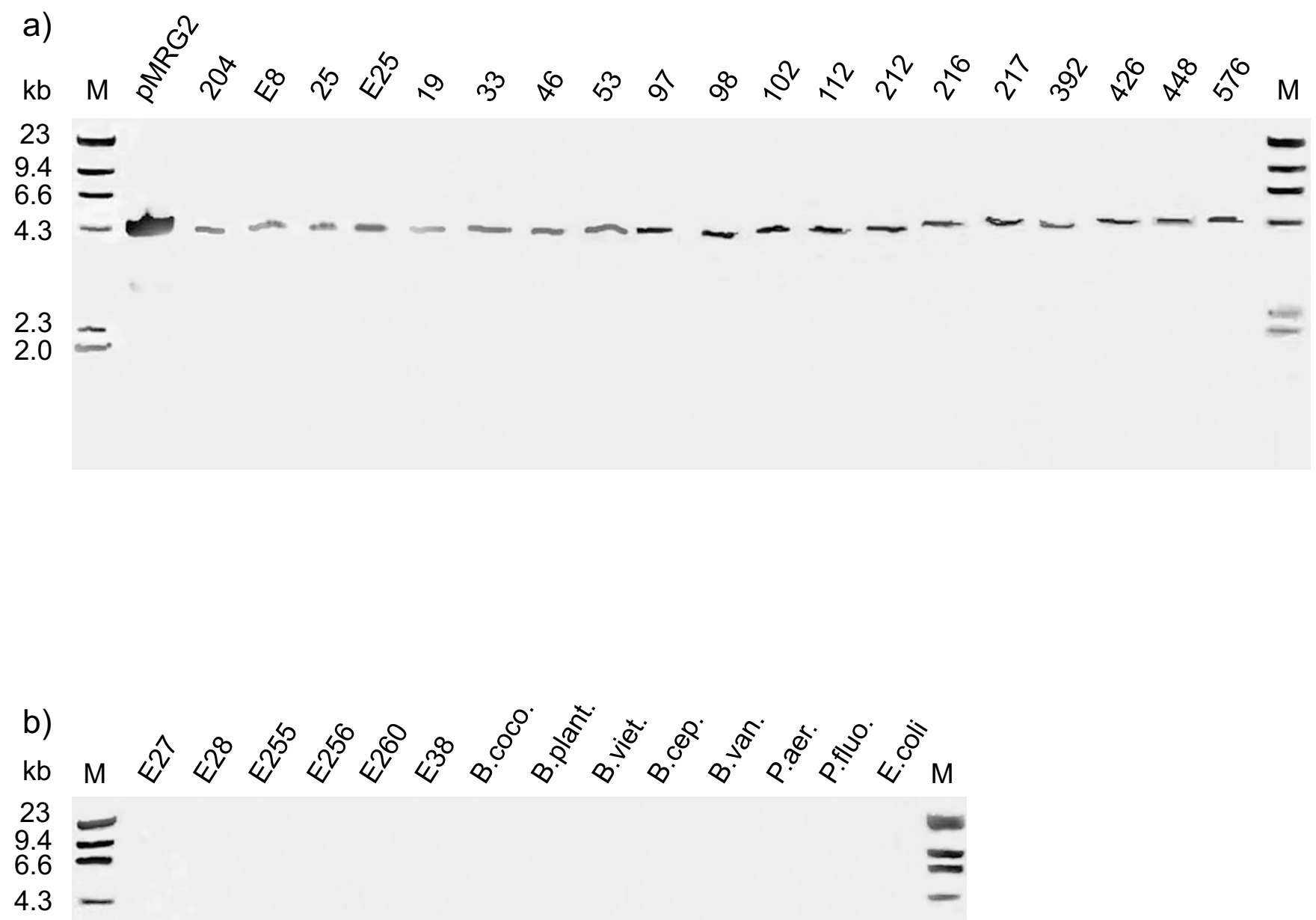

2.3

2.0

\section{Figure 2}

Southern blot hybridisation of EcoRI-digested genomic DNA from different bacterial species using a digoxigenin-labeled oligonucleotide probe for $\operatorname{mrgRS}$ : a) B. pseudomallei isolates, PMRG2 contains a $4.3 \mathrm{~kb}$ EcoRI fragment of $B$. pseudomallei genomic DNA, spanning most of the mrgRS locus, inserted in PUCI 8 and digested with EcoRI b) $B$. thailandensis, other Burkholderia species, including B. cocovenenans (B. coco.), B. plantarii (B. plant.), B. vietnamiensis (B. viet.), B. cepacia (B. cep.) and B. vandii (B. van.), Pseudomonas aeruginosa (P. aer.), Pseudomonas fluorescens (P. fluo.) and $E$. coli. Lane $M$, $\lambda$-Hindlll markers with molecular sizes (in kilobases) indicated on the left. See Table I for isolate details. All of the samples in the figure were separated on the same single agarose gel, transferred to the same single nylon membrane, and hybridized in the same single hybridization tube using the same labeled probe. The image of the resulting single Southern blot is reproduced in the figure as 2 panels, a) and b), for convenience and clarity and therefore PMRG2 represents a positive control for all samples.

raises the possibility that birds might act as a reservoir of B. pseudomallei and pose a risk for the transmission of active melioidosis to other species [38].
The expression of the 24-28 kDa MrgR bands was substantially reduced when $B$. pseudomallei 204 was cultured at $25^{\circ} \mathrm{C}$ compared with 37 or $42^{\circ} \mathrm{C}$ but was mostly unaf- 


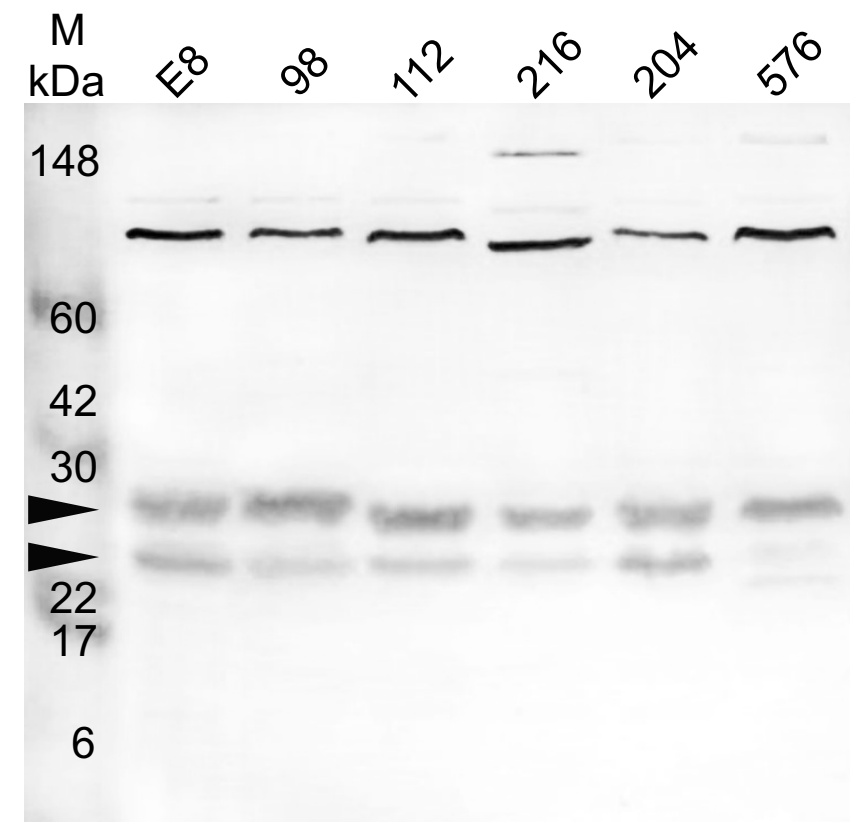

Figure 3

Western blot probed with an affinity purified antibody, antiMrgR, showing the detection of MrgR in whole cell lysates from 6 isolates of $B$. pseudomallei grown at $37^{\circ} \mathrm{C}$. The isolate number is indicated above each lane. Lane $\mathrm{M}$ : molecular weight markers indicated in kilodaltons $(\mathrm{kDa})$. See Table I for isolate details. Arrows indicate the expected position of the $24 \mathrm{kDa}$ MrgR protein and slightly larger phosphorylated forms of MrgR. See text for details.

fected by different $\mathrm{pH}$ or $\mathrm{NaCl}$ concentration, although at $25^{\circ} \mathrm{C}$ and $0.15 \% \mathrm{NaCl}$ a small increase in expression was observed at pH 5 (Figure 6). This was particularly evident at $42^{\circ} \mathrm{C}$, where the lower molecular weight band that we believe represents the dephosphorylated form of MrgR is absent, demonstrating that at higher temperatures the gene is co-ordinately up-regulated. It is possible that at least some of the observed effects could be explained by differences in gene expression at different growth stages, but because equivalent quantities of protein from each sample were used in these studies and the expression of the $80 \mathrm{kDa}$ immunoreactive band was mostly unaffected by $\mathrm{pH}$, salt concentration or temperature then this possibility seems unlikely. A similar response was observed for MrgS expression (Figure 7).

\section{Cloning and sequence analysis of mrgRS downstream flanking region}

Four ORFs, referred to here as ORFs1-4, were identified downstream from the $\mathrm{mrgRS}$ locus (Figure 1) and the conceptual translations of each ORF were analysed. The sequence and arrangement of the ORFs is available on GenBank (accession no. DQ418486). We cloned, sequenced and analyzed the genes well before the com-

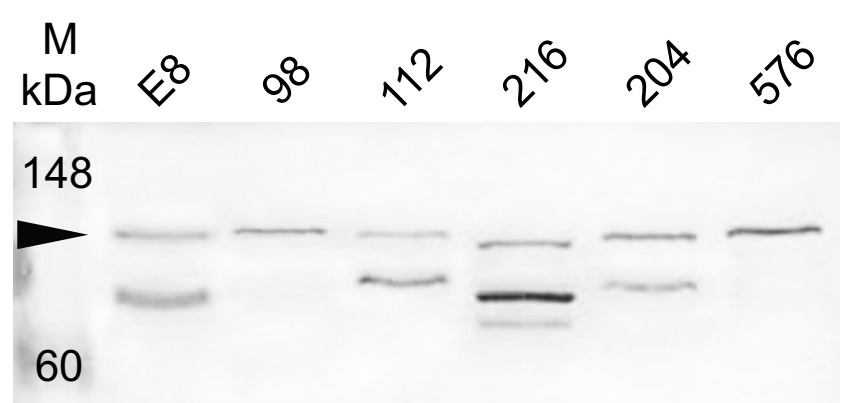

42

30

22

17

6

\section{Figure 4}

Western blot probed with an affinity purified antibody, antiMrgS, showing MrgS in cell lysates from 6 isolates of $B$. pseudomallei grown at $37^{\circ} \mathrm{C}$. The isolate number is indicated above each lane. Lane M: molecular weight markers indicated in kilodaltons $(\mathrm{kDa})$. See Table I for isolate details. Arrow indicates the expected position of the $118 \mathrm{kDa}$ MrgS protein. Smaller bands may represent processed forms of MrgS. See text for details.

pletion of the B. pseudomallei genome sequence, which is now known to correspond to the region of the $B$. pseudomallei K96243 genome sequence containing locus tags BPSL1635-1637. These locus tags do not exactly match ORF2 and ORF3 that we have identified. Indeed, there are differences in the nucleotide sequences and also in the gene and protein annotations for this region of the two completed genome sequences, B. pseudomallei K96243 and $1710 \mathrm{~b}$ that are listed on GenBank. The strong transcriptional termination sequence following the $\mathrm{mrgS}$ gene suggests that the downstream sequences are transcribed separately. ORF1 (BPSL1635) is immediately downstream of $m r g S$ and transcribed in the same direction and the predicted protein $(31,527 \mathrm{kDa})$ is similar to sensor transduction proteins containing EAL (GluAlaLeu) domains, such as the oxygen sensing protein of E. coli O157:H7 (31\% identity) and BvgR of B. pertussis (25\% identity). EAL domains are found in a wide variety of bacterial signalling proteins where they can act to stimulate degradation of the second messenger, cyclic di-GMP, and may function as a diguanylate phosphodiesterase [39]. Enzymatically 


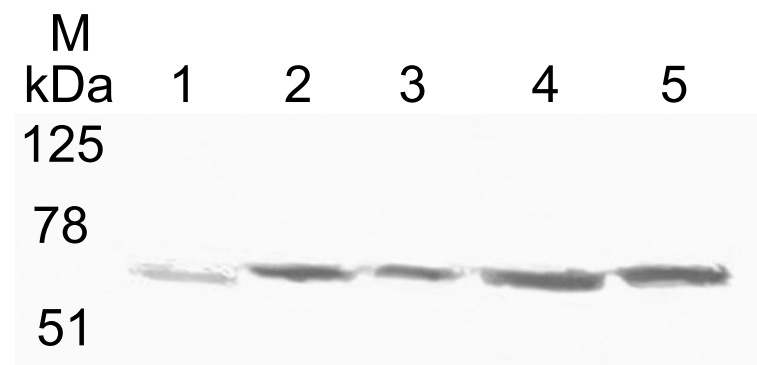

30

\section{Figure 5}

Western blot showing the recognition of MBP-MrgR fusion protein by antibodies in convalescent sera pooled from 6 melioidosis patients. Lane I: Uninduced cells, lane 2: cells induced for $3 \mathrm{~h}$ with IPTG, lane 3: amylose resin purified cell extract, lane 4: crude cell extract, and lane 5: insoluble matter, lane 6: purified maltose binding protein. Lane M: molecular weight markers indicated in kilodaltons $(\mathrm{kDa})$.

active and inactive forms have been described [39] and the variation in EAL domain sequences may reflect the convergent evolution of successful structure-function motifs rather than the usual primary sequence similarity. This structure is conserved in the conceptual translation of ORF1. Although the precise functions of many of these proteins are unknown, their open reading frames are within or are tightly linked to operons with well-defined functions. For example, $b v g R$ is required for regulation of all known bvg-repressed genes in B. pertussis, and is located on a separate regulatory unit immediately downstream from the bvgAS locus encoding a two-component regulatory system that upregulates virulence gene expression in $B$. pertussis [40]. The similarities between the genomic organisation in bvgAS-bvgR and mrgRS-ORF1 together with the fact that both BvgAS and MrgRS are members of the two-component signal transduction family allows for the possibility that ORF1 may also act to repress the mrgRS locus.

Further downstream and in the reverse direction of the complementary strand three open reading frames were identified, ORF2, ORF3, and ORF4. For ORF2, the predicted protein $(28,251 \mathrm{kDa})$ is similar to the arginine/serine rich regions of functionally diverse proteins that are important for binding RNA and DNA and for protein-protein interactions [41], such as LigA of Burkholderia cenocepacia (33\% identity). The conceptual translation of ORF3 $(16,856 \mathrm{kDa})$ is similar to a variety of transmembranetransport proteins, such as the $\mathrm{ABC}$ thiamine transporter of Roseovarius nubinhibens ( $31 \%$ identity) and capsular

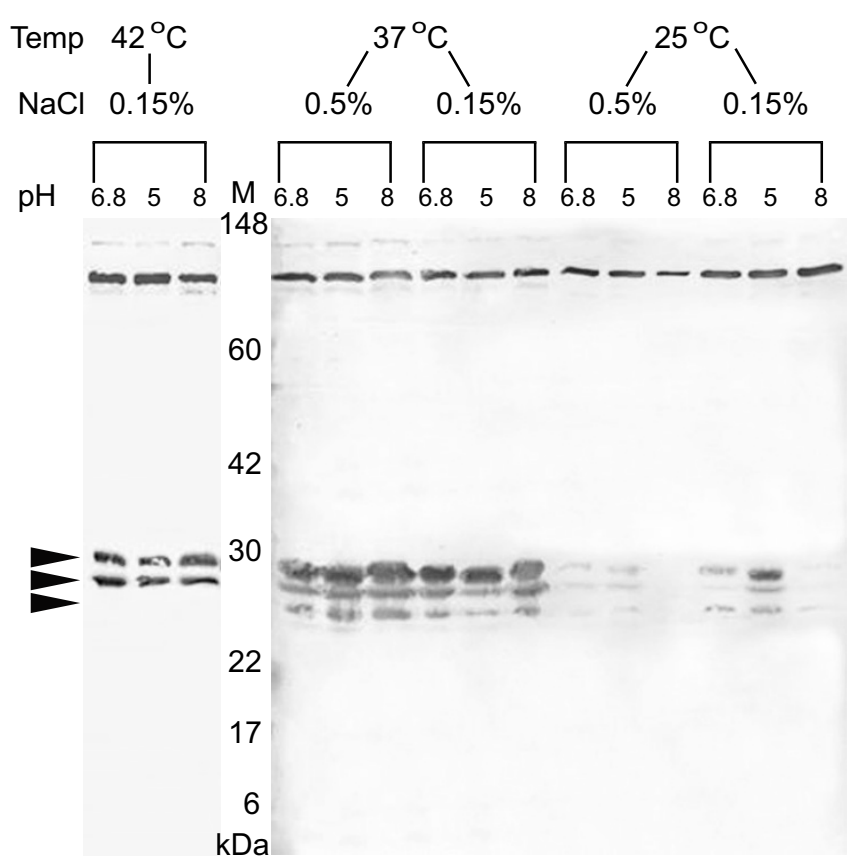

Figure 6

Expression of MrgR in B. pseudomallei 204 cultured under different combinations of temperature, $\mathrm{pH}$ and $\mathrm{NaCl}$ concentration. Western blots of whole cell lysates were probed with anti-MrgR. The identity of each lane is indicated at the top. Lane M: molecular weight markers indicated in kilodaltons $(\mathrm{kDa})$. Arrows indicate the expected position of the 24 $\mathrm{kDa}$ MrgR protein and slightly larger phosphorylated forms of MrgR.

polysaccharide export protein of Rhodobacter sphaeroides (28\% identity), and possesses 2 transmembrane helices (TopPRED2 scores 0.71 and 0.88). For ORF4 (BPSL1637), the predicted protein $(39,493 \mathrm{kDa})$ has a lipase (class 3$)$ domain spanning residues 103-252 and including the lipase serine active site [42], GHSLG, located at positions 187-191. This protein lacks the features usually associated with a signal peptide, although this is not an essential component for secretion [43], and is strongly predicted to be secreted by non-classical mechanisms, SecP score = 0.933881 (B. pseudomallei isolate 204) and 0.930609 (B. pseudomallei isolate 112) [44]. B. pseudomallei has been shown to utilize a wide variety of lipid substrates $[45,46]$ and to confirm the presence of an extracellular lipase concentrated culture supernatants were prepared from all isolates of B. pseudomallei (Table 1). Lipase activity was determined to be present in all samples using the fluorogenic substrate 4-methylumbelliferyl oleate and so it is possible that this gene could be expressed, secreted and contribute to this lipase activity, either alone or in concert with other molecules. 


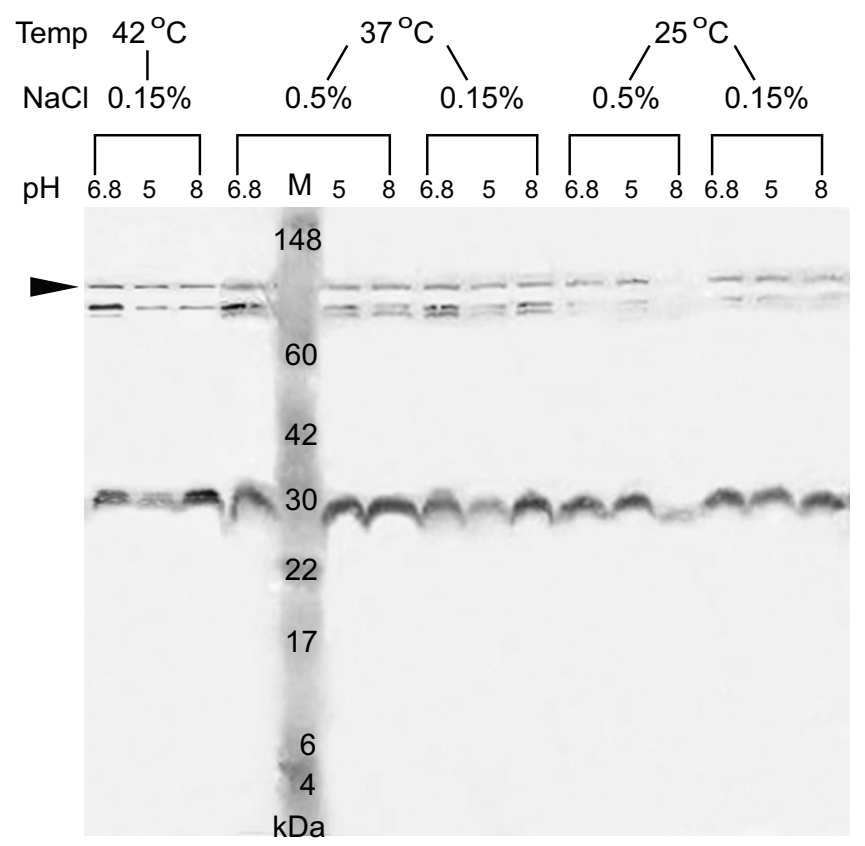

\section{Figure 7}

Expression of MrgS in B. pseudomallei 204 cultured under different combinations of temperature, $\mathrm{pH}$ and $\mathrm{NaCl}$ concentration. Western blots of whole cell lysates were probed with anti-MrgS. The identity of each lane is indicated at the top. Lane M: molecular weight markers indicated in kilodaltons $(\mathrm{kDa})$. Arrow indicates the expected position of the 118 kDa MrgS protein.

The full response regulator gene $m r g R$ is present in the genome of many B. mallei isolates but $\mathrm{mrgS}$ and the downstream flanking region are absent. Instead, ORFs immediately downstream of the $m r g R$ homolog in $B$. mallei have strong homology to penicillin amidase, carbamoyl transferase and transposase and their presence provides circumstantial evidence that transposition may partly explain the absence of this region in B. mallei.

\section{Restriction fragment length analysis of the mrgRS downstream flanking region}

Three oligonucleotide probes, FR1, FR2 and FR3, covering almost $5 \mathrm{~kb}$ of the $B$. pseudomallei genome downstream from $\operatorname{mrgRS}$ (Figure 1) were used to investigate EcoRI digests of genomic DNA from different $B$. pseudomallei strains as well as $B$. thailandensis (Table 1). No signal was obtained with any of the probes in any of the B. thailandensis isolates. Furthermore, this region is not present in the recently completed $B$. thailandensis E264 genome sequence [33] that is available on GenBank.

The FR1 probe spans the distal end of $m r g S$ and 285 nucleotides further downstream from the $m r g S$ stop codon including an EcoRI site, and was expected to hybridise two
EcoRI genomic DNA fragments of 684 and 592 bp. These two bands were present in most isolates of $B$. pseudomallei except 392 and H55 which possessed the 592 bp fragment only (data not shown). In isolate 392 this band is very strongly stained and may represent a doublet. In addition, H55 possessed an additional unique band of approximately $4.5 \mathrm{~kb}$. There were no obvious variations in fragment size between isolates in the adjoining region that was probed with FR2 (data not shown). However, the region probed with FR3, which lacked an internal EcoRI site, revealed two distinct patterns between $B$. pseudomallei isolates. One pattern indicated the presence of a single band of $\sim 1781$ bp in seven isolates, while the other pattern demonstrated a band of $\sim 1421$ bp in nine isolates (Figure 8). To determine the reasons for the difference, we sequenced this part of the genome of isolates possessing each size of EcoRI fragment.

Alignment of 1472 nucleotides covering the same region of the genomes of isolates 112 and 204 revealed 19 base substitutions including one substitution of "A" for " $G$ " at position 1119 which introduces an EcoRI site within ORF4 as described below (GenBank accession no. DQ418487). An examination of the genome sequences of B. pseudomallei that are available on GenBank showed that 8 of the 10 strains possess the same modification at this position as isolate 112. Among all of the B. pseudomallei isolates, including 112 and 204, there are between 4 and 19 nucleotide substitutions within this 1472 bp region. Furthermore, isolates that possess the "A" substitution at position 1119 have substantial modifications to sequences flanking this region of the genome (Figure 1), including the presence of a $450 \mathrm{bp}$ insertion (between nucleotides 9565 and 9566 of GenBank accession no. DQ418486) encoding a product with homology to a bacteriophage phiE125 gp30 protein (GenBank accession no. AF447491), and 650 bp sequence homologous to mutator type transposases from a wide variety of bacterial species, including Ralstonia solanacearum, Pseudomonas syringae, and B. thailandensis. The transposase is probably inactive because of the organization of the sequence, which includes at least 4 stop codons and incomplete reading frames.

Among the isolates of $B$. pseudomallei that were examined up to 16 nucleotide substitutions fall within ORF4 and although most of these, including the "A" for "G" substitution which introduces the EcoRI site described above, do not alter the predicted primary translation there are from 2-4 conservative amino acid substitutions. Non-conservative substitutions which are present, G180E (6/12 isolates) and V229A (10/12 isolates), flank the serine active site and may have functional consequences (Figure 9). Lipases hydrolyze long-chain acyl-triglycerides, a process that usually involves activation of the enzyme at the lipid/ 


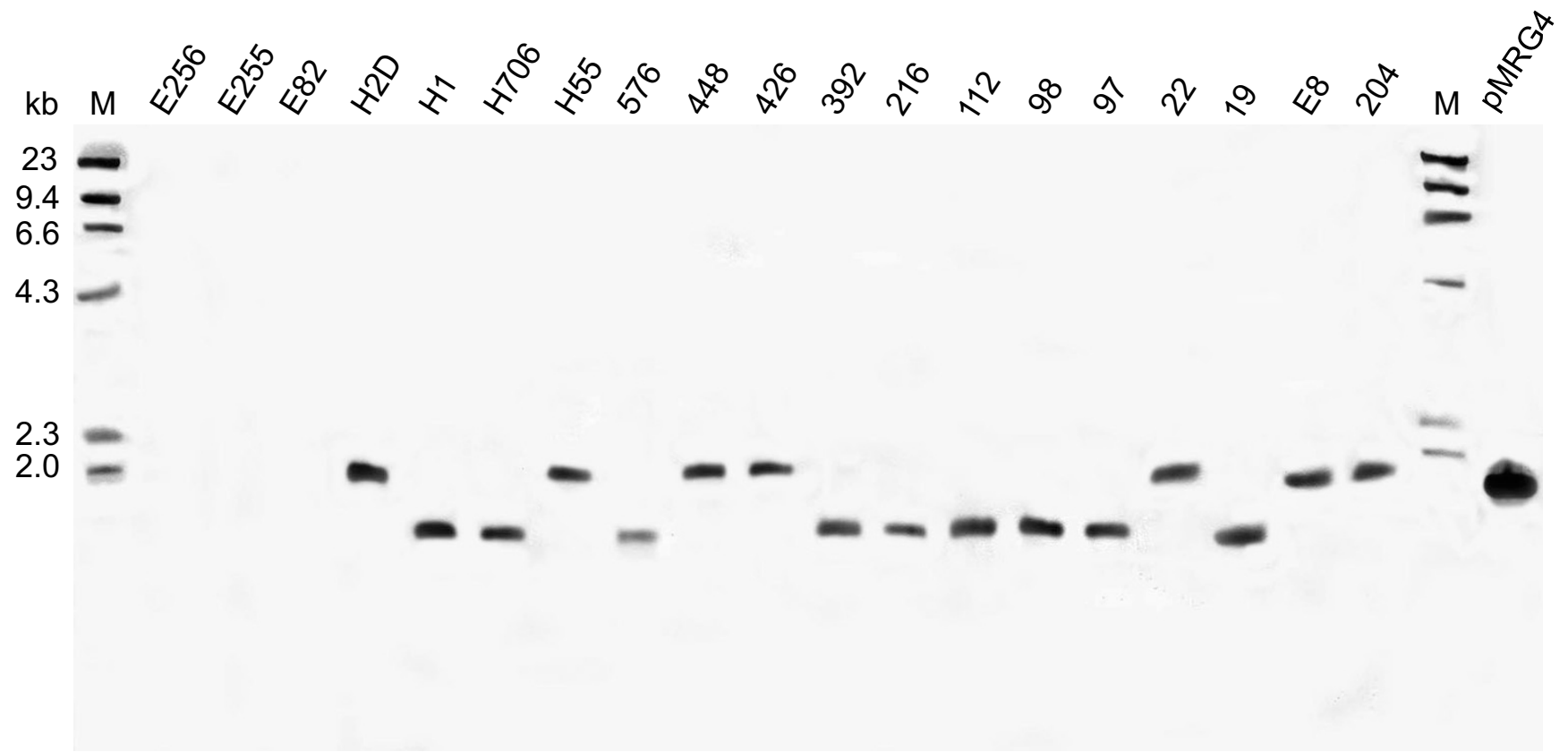

Figure 8

Southern blot hybridisation of EcoRI-digested genomic DNA from isolates of B. pseudomallei and B. thailandensis using oligonucleotide probe FR3. Lane M, $\lambda$-HindIII markers with molecular sizes (in kilobases) indicated on the left. Lane pMRG4 contains an $8.4 \mathrm{~kb}$ Bcll fragment of the $B$. pseudomallei 204 genome spanning most of the mrgRS locus and $5 \mathrm{~kb}$ downstream, inserted in the phagemid pBK-CMV which was excised from $\lambda$ ZAP Express and digested with EcoRI. See Table I for isolate details.

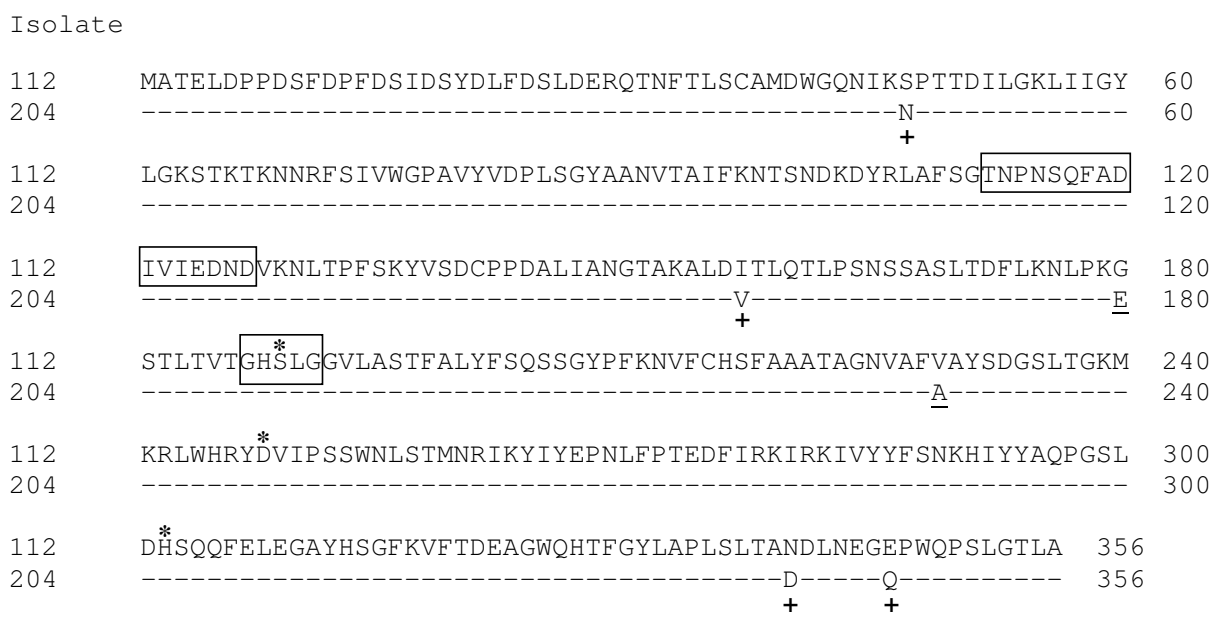

Figure 9

Alignment of lipases of B. pseudomallei isolates II 2 and 204. Boxes enclose the "lid" motif (residues II2-I27) and serine active site (residues 187-191). Asterisks mark the catalytic triad of serine, aspartic acid and histidine. +: conservative amino acid substitutions. Non-conservative amino acid substitutions are underlined. The 6 substitutions that are marked were also present in many of the B. pseudomallei genome sequences of 10 isolates that are available in GenBank: S47N: 10 isolates; II $57 \mathrm{~V}$ : 10 isolates; GI80E: 5 isolates; V229A: 9 isolates; N340D: 4 isolates; E346Q: 3 isolates. Other substitutions were also found occasionally: S252F: I isolate; D34IA: I isolate; V249L: I isolate. 
water interface, and are known to facilitate the colonisation of plants by fungi and bacteria [47]. The active site is hidden until activation occurs when the "lid" covering the active site opens, exposes the active site catalytic triad, S$\mathrm{D}-\mathrm{H}$, and allows access to the substrate. Mutating specific residues flanking the active site can affect this process, for example by altering the enantiomeric selectivity of B. cepacia lipase [48]. B. pseudomallei is often associated with disease among workers in rice fields in Thailand and it has been suggested that it may interact closely with plants by using a plant pathogen-like TTS gene cluster [49-51]. In this case, the delivery of lipases could play an essential role in the colonization of plants by $B$. pseudomallei.

Studies investigating the molecular diversity of different isolates of $B$. pseudomallei using a wide variety of methods have demonstrated that although distinct groupings can be defined substantial diversity exists and many isolates do not fall into readily definable groupings or clinical outcomes [3]. Recently, whole genome DNA and RNA spotted arrays have been used to examine large scale genomic variation among different Burkholderia species [33,34]. This work has demonstrated the close relationship that exists between the non-pathogenic environmental saprophyte $B$. thailandensis, the obligate equine parasite $B$. mallei and the opportunistic pathogen $B$. pseudomallei and particularly between $B$. mallei and $B$. pseudomallei, supporting work by Godoy et al. [52] who considered B. mallei to be a clone of $B$. pseudomallei rather than a separate species. Kim et al. [33] showed that the expression of a substantial number of genes is highly conserved between all 3 species and suggested that the evolution of small sets of genes rather than large scale acquisitions and losses define the different adaptations of each species. On the other hand, Ong et al. [34] proposed that the same 3 species may have diverged through the loss of large chromosomal segments and defined 3 distinct molecular subtypes of $B$. pseudomallei on the basis of regions of difference, constituting areas of DNA recombination that are often characterized by open reading frames (ORFs) encoding products related to phage proteins, transposase or integrase proteins. However, apart from rRNA genes [53] few studies have assessed the extent of variation at specific loci in B. pseudomallei.

The diversity of organisms in tropical countries in which melioidosis is endemic and the frequent interactions that may be possible in that environment and within the human host could create opportunities for genetic change [54]. However, a mutation that confers a selective advantage in one environment is unlikely to be a benefit in all environments [55]. Winstanley et al. [56] assessed the extent of variation in the flagellin genes of $B$. pseudomalle $i$ by comparing the sequences that were obtained from environmental and clinical isolates of the pathogen. The sequences showed either $100 \%$ identity or differed by a single nucleotide demonstrating a remarkably conservative nature in these genes. Here, we found a consistent variation in a small region of the $B$. pseudomallei genome downstream from the mrgRS locus involving up to 19 nucleotide substitutions including one which changes GAGTTC to GAATTC, the recognition sequence for the restriction enzyme EcoRI. The consequent restriction fragment length polymorphism (RFLP) was shown to separate $B$. pseudomallei isolates from clinical and environmental sources and from spatially and temporally separate origins, into two distinct groups of almost equal proportions. There was no apparent association between the source of the isolates, the date and place of isolation, and the RFLP pattern. Nevertheless, the substitutions represent a stable genetic modification since they have been retained over time. Furthermore, a search of the genome sequences for $B$. pseudomallei isolates that are available on GenBank revealed the presence of the same modification in many of the isolates. While it is possible that these sequence differences may have occurred at random, the almost equal distribution of the polymorphism among the isolates, the presence of a $450 \mathrm{bp}$ insertion and the close proximity of an inactive transposase suggest that it is much more likely that some process of selection has occurred. For example, differences in primary or secondary host factors may act to select isolated subpopulations according to transmission route or host immune genotypes and play a role in the selection for a mutation or recombination event arising within a bacterial population $[57,58]$. How this may have occurred in the isolates we examined here is not known. Ong et al. [34] described $B$. pseudomallei strain subtypes isolated from different primary hosts, pigs (G1 strains) and melioidosis patients (G2 strains), and so we propose that a selective process involving primary hosts or other vectors, including amoebae, fungi or plants [59-61], may have played a role.

\section{Conclusion}

This work was initiated and completed well before the $B$. pseudomallei genome sequence was published. Although the completion of the B. pseudomallei genome sequence has provided a huge body of annotated nucleotide sequence data and an examination of this data revealed at least 33 potential two-component systems in the sequence annotations, very few of the putative genes have been specifically confirmed to be expressed at the protein level in different $B$. pseudomallei strains. In fact, there are substantial discrepancies in the gene and protein annotations for the completed genome sequences of $B$. pseudomaIlei isolates K96243 and 1710b that are available on the GenBank database. Our work demonstrates that $m r g R$ and $m r g S$ are present and expressed as protein in a variety of $B$. pseudomallei isolates and that the expression of the locus is temperature-regulated which is an essential step that must 
be completed before pursuing more complex studies aimed at understanding the biological function and pathogenic significance of the $\mathrm{mrgRS}$ locus. A similar approach will be necessary to prove the specific protein expression of each of the putative genes that have been identified in the $B$. pseudomallei genome rather than simply assuming that all open reading frames that are annotated in the nucleotide sequence of the genome are expressed as the conceptually translated protein.

Because of its' nutritional and environmental adaptability, $B$. pseudomallei has the potential to spread to areas of the world outside southeast Asia and northern Australia. Two-component transduction systems are a major mechanism by which bacteria regulate adaptive responses to environmental stimuli [18]. Although there have been extensive studies of the biology of $B$. pseudomallei, very few of these have investigated the influence of environmental factors on gene expression and the adaptive responses of the bacterium. We have identified and characterized a two-component transduction system from $B$. pseudomalle $i$ that is present and expressed in a variety of strains of the bacterium, encoding proteins that are most similar to the regulators of capsular synthesis in other bacteria. In $B$. pseudomallei, the expression of these proteins is regulated in response to temperature rather than $\mathrm{pH}$ or salinity and they are more strongly expressed at temperatures found in mammalian and avian hosts. The recognition of MrgR by antibodies in convalescent sera from melioidosis patients suggests that the mrgRS locus may have a role in regulating adaptive responses during the course of infection. Because the expression of the genes is increased at higher temperatures then the adaptive responses they control may be particularly important during the initial phases of infection.

It has been proposed that B. mallei, B. pseudomallei, and B. thailandensis represent 3 states of ecological niche adaptation, namely, obligate pathogen, opportunistic pathogen, and saprophyte, respectively [33]. The 3 species are very closely related and the mechanisms of evolutionary divergence are subject to debate $[33,34,52]$. The absence of the $m r g R S$ locus and downstream flanking region from the genome of $B$. thailandensis shows that it is not essential for a non-pathogenic existence. Because of the similarities in gene organization and structure with other signal transduction systems involved in phase change and the regulation of virulence gene expression, it is possible that $\mathrm{mrgS}$ and the downstream ORFs may have a similar role in adaptive responses of $B$. pseudomallei, which in the case of $m r g S$ is regulated by changes in temperature. The absence of this region in B. mallei suggests that this function is no longer required but $m r g R$ may still have a regulatory role.
Nucleotide sequence accession numbers

[GenBank:DQ418486, GenBank:DQ418487]

\section{Methods}

\section{Bacterial strains and growth conditions}

Bacterial strains used in this study are listed in Table 1. All strains of Burkholderia species were grown at $37^{\circ} \mathrm{C}$, except B. plantarii and $B$. vandii which were grown at $25^{\circ} \mathrm{C}$, on Luria-Bertani (LB) agar or broth, statically. Pseudomonas aeruginosa and Pseudomonas fluorescens were grown on nutrient agar at $37^{\circ} \mathrm{C}$. The identity of $B$. pseudomallei was confirmed by the API 20NE biochemical test [62]. For expression studies, $10 \mathrm{ml}$ LB broths containing $\mathrm{NaCl}$ $(0.15,0.5$ or $2.2 \% \mathrm{w} / \mathrm{v})$ were adjusted to $\mathrm{pH} 5,6.8$ or 8 and a standardized inoculum of $10^{7}$ cells was added and incubated for $48 \mathrm{~h}$ at 25,37 or $42^{\circ} \mathrm{C}$. E. coli strains were cultured on LB agar or broth [63] and when required, culture media were supplemented with IPTG $(100 \mu \mathrm{M})$, X-gal $\left(100 \mu \mathrm{g} \mathrm{ml}^{-1}\right)$, ampicillin $\left(100 \mu \mathrm{g} \mathrm{ml}^{-1}\right)$, chloramphenicol $\left(25 \mu \mathrm{g} \mathrm{ml}^{-1}\right)$ or kanamycin $\left(25 \mu \mathrm{g} \mathrm{ml}^{-1}\right)$.

\section{DNA manipulations}

Restriction enzyme digestions, DNA blunting and kinasing, DNA ligation, bacterial transformation and DNA hybridisation were performed according to standard methods [63]. Plasmid DNA was isolated using the Miniprep plasmid DNA extraction kit (BioRad), lambda DNA was purified using the Wizard $\lambda$ prep DNA purification kit (Promega) and DNA fragments, PCR products and ligation mixtures were recovered using the Prep-a-gene DNA purification kit (BioRad). Genomic DNA was extracted using the Puregene D-6000 DNA isolation kit (Gentra Systems) and quantified by comparison with lambda DNA standards (Sigma Aldrich) using digital images of $1 \%$ agarose gels stained with ethidium bromide.

\section{Preparation of oligonucleotide probes}

PCR primers (Sigma Genosys), 5'-GATTTCACGATGCATCAGGCGAAC-3' and 5'-TTCTGGATCGCCGCGATGTCCGTG-3', were derived from the sequences of response regulator genes from other bacterial species to amplify a 377 bp sequence from B. pseudomallei 204 genomic DNA. The PCR reaction contained 1 unit Taq DNA polymerase in reaction buffer (Roche), $1.5 \mathrm{mM} \mathrm{MgCl} 2,10 \mathrm{pmol}$ of

Table 2: PCR primers for preparing oligonucleotide probes FRI, FR2, and FR3

\begin{tabular}{lc}
\hline Primer & Sequence 5'-3' \\
\hline FRI forward & ATGATGGACGGTTTCCAGTTGCTC \\
FRI reverse & AACGTTAAATCAAGTCGCGGGTGG \\
FR2 forward & AGAGCGCTGTCGCAACTGAATCTG \\
FR2 reverse & TCGCTTCGCTTGCTGAGAAA \\
FR3 forward & GGTCCGGGCCAAATATTACGATCC \\
FR3 reverse & AGCGGAACCAATCCGAACTCACAG
\end{tabular}


each primer, $0.2 \mathrm{mM}$ of each $\mathrm{dNTP}$ and $10 \mathrm{ng}$ genomic DNA. Reactions were placed at $96^{\circ} \mathrm{C}$ for $2 \mathrm{~min}$, followed by 35 cycles consisting of $96^{\circ} \mathrm{C}$ for $30 \mathrm{~s}$, annealing at $45^{\circ} \mathrm{C}$ (1st cycle), $50^{\circ} \mathrm{C}$ (2nd and 3 rd cycles) and $60^{\circ} \mathrm{C}$ (remaining 33 cycles) for $30 \mathrm{~s}, 72^{\circ} \mathrm{C}$ for $90 \mathrm{~s}$ and a final extension at $72^{\circ} \mathrm{C}$ for $5 \mathrm{~min}$. Amplicons were analysed in $1 \%$ agarose gels, purified and subcloned into pUC18 using E. coli DH5 $\alpha$. Cloned DNA was fully sequenced in both directions (MWG Biotech). Following confirmation, the insert was excised from pUC18 by EcoRI and PstI digestion, purified by agarose gel electrophoresis and labelled with digoxigenin-11-dUTP (Roche).

For RFLP analysis of 4994 bp of the genome downstream from the $m r g R S$ locus, three pairs of PCR primers (Table 2 ) were designed on the basis of nucleotide sequence data (GenBank accession no. DQ418486) to amplify oligonucleotide probes to sequentially examine 5 contiguous EcoRI fragments of the genome. The probes were designated FR1, a 665 bp probe targeting a 1276 bp segment with an internal EcoRI site and including the $m r g S$ stop codon, FR2, a 1062 bp probe targeting a 1937 bp segment with an internal EcoRI site, and FR3, a 1136 bp probe targeting a 1781 bp segment. The PCR reaction contained 1 unit Taq polymerase in reaction buffer (Roche), $1.5 \mathrm{mM}$ $\mathrm{MgCl}_{2}, 24$ pmol of each primer, $0.2 \mathrm{mM}$ of each dNTP and $10 \mathrm{ng}$ genomic DNA. Reactions were placed at $96^{\circ} \mathrm{C}$ for 2 min, followed by 35 cycles of $96^{\circ} \mathrm{C}$ for $40 \mathrm{~s}, 65^{\circ} \mathrm{C}$ for 40 $\mathrm{s}, 72^{\circ} \mathrm{C}$ for $90 \mathrm{~s}$ and a final extension at $72^{\circ} \mathrm{C}$ for $5 \mathrm{~min}$. Amplicons were analysed in 1\% agarose gels, purified and subcloned into pUC18 using E. coli DH5 $\alpha$. Cloned DNA was fully sequenced in both directions (MWG Biotech) and was labelled with digoxigenin-dUTP (Roche).

\section{Construction and screening of genomic DNA libraries}

$B$. pseudomallei 204 chromosomal DNA libraries were constructed using $\lambda$ GEM-11 and $\lambda$ ZAP Express vectors. For $\lambda$ GEM-11, genomic DNA was partially digested with Sau3A to yield fragments between 9 and $23 \mathrm{~kb}$ which were inserted into the BamHI site and packaged recombinants were plated on E. coli LE392 using NZCYM-agarose containing $0.2 \%$ maltose (Promega). For $\lambda Z A P$ Express, genomic DNA was completely digested with $B c l$ I and ligated into the BamHI site, packaged, and propagated on E. coli XL1-Blue. Plasmid DNA, in the form of the kanamycin-resistant phagemid pBK-CMV, containing cloned
DNA inserts was excised from $\lambda$ ZAP Express using helper phage and E. coli XLOLR (Stratagene).

For screening $B$. pseudomallei genomic libraries, phage plaques were overlaid with gridded nitrocellulose filters (Schleicher and Schuell) for $30 \mathrm{~min}$ at $4^{\circ} \mathrm{C}$. Filters were processed for hybridization with a labelled oligonucleotide probe at high stringency overnight at $68^{\circ} \mathrm{C}$ according to standard methods [63]. Positive phage plaques were detected with anti-digoxigenin antibody (Roche).

DNA sequencing and sequence analysis of cloned products Both strands of cloned DNA were sequenced (MWG Biotech) using either M13 universal and reverse primers or custom synthesized primers (Sigma Genosys). Gene sequences have been deposited in the GenBank database (GenBank accession nos. DQ418486, DQ418487). Gene promoter predictions were made using software provided by Berkeley Drosophila Genome Project [64]. Homology and conserved domain searches were conducted using BLAST software provided by NCBI [65]. Software provided by the Swiss Institute of Bioinformatics [66] and Institut Pasteur [67] was used to analyse secondary structure (PHDtopology), hydrophobicity (Pepwindow), helix-turn-helix motifs (Helixturnhelix), and transmembrane regions (TopPRED2, DAS). Multiple amino acid sequence alignments were performed using MultAlin software [68]. SecretomeP 2.0 [44] was used to predict nonclassical protein secretion [69].

\section{Southern blotting}

Genomic DNA (3 $\mu \mathrm{g})$ was completely digested with EcoRI and the fragments separated in 1\% agarose gels in TBE buffer, depurinated, denatured and neutralized using standard methods [63]. DNA was capillary blotted onto positively charged nylon membranes (Amersham Biosciences) and fixed to the membrane using UV irradiation. The blots were prehybridized, hybridized with the labelled oligonucleotide probe and developed, according to standard methods [63].

\section{Synthetic peptides and production of affinity purified antibodies}

Synthetic peptides consisting of 9 amino acid residues, DTNVDLINC and RKFYSLESN, corresponding to amino acids 206 to 214 located toward the C-terminus of MrgR

Table 3: Dilutions of primary and secondary antibodies for Western blotting

\begin{tabular}{ccccc}
\hline Primary Antibody & Dilution & Secondary Antibody & Dilution & Source \\
\hline Anti-MrgR & $1: 500$ & Swine Anti-rabbit IgG & I:2000 & Bethyl Labs \\
Anti-MrgS & $1: 300$ & Swine Anti-rabbit lgG & $1: 1000$ & Bethyl Labs \\
Anti-MBP & $1: 1000$ & Swine Anti-rabbit IgG & $1: 2000$ & NEB \\
Convalescent sera pooled & $1: 300$ & Rabbit Anti-human IgG & $1: 1000$ & Ty Pitt, HPA, London \\
from 6 melioidosis patients & & & &
\end{tabular}


and amino acids 14 to 22 located in the $\mathrm{N}$-terminus of MrgS, respectively, were synthesized, conjugated to keyhole limpet hemocyanin (KLH) and used to immunize rabbits (Bethyl Laboratories). To facilitate coupling to maleimide-activated KLH a glycine residue was attached to the C-terminus of the MrgR oligopeptide and a cysteine residue was attached to the N-terminus of the MrgS oligopeptide. Antibodies were purified from the hyperimmune serum of immunized rabbits by affinity chromatography using a peptide-Sepharose matrix, filter sterilized and stored at $4{ }^{\circ} \mathrm{C}$. The affinity purified antibodies, anti-MrgR and anti-MrgS, were tested for antigen recognition and specificity as described in Additional file 1, Additional file 2 and Additional file 3.

\section{Preparation of B. pseudomallei protein samples and Western blotting}

Cells from $1 \mathrm{ml}$ aliquots of $B$. pseudomallei cultures that had been prepared as described above were centrifuged $\left(4,000 \mathrm{~g}, 10 \mathrm{~min}, 4^{\circ} \mathrm{C}\right)$, washed in PBS and resuspended in lysis buffer $(0.75 \mathrm{M}$ Tris- $\mathrm{HCl} \mathrm{pH} 8.8$ containing $0.2 \%$ SDS). B. pseudomallei broth culture supernatants containing extracellular products (ECPs) were centrifuged $\left(15,000 \mathrm{~g}, 10 \mathrm{~min}, 4^{\circ} \mathrm{C}\right)$ and the supernatant was concentrated 250-fold using Amicon Minicon Miniplus units, 10 $\mathrm{K}$ nominal mw cutoff (Millipore). The total protein concentration of cell lysates and ECPs was determined using a protein assay kit (Bio-Rad). Lipase activity in the concentrated supernatants was determined by comparison with uninoculated broth using the fluorogenic substrate 4methylumbelliferyl oleate (Sigma). For each sample, equivalent amounts of $B$. pseudomallei whole cell lysate ( 5 $\mu \mathrm{g})$ or ECPs $(2 \mu \mathrm{g})$, were diluted in Laemmli buffer and separated on $12 \%$ polyacrylamide-SDS gels. Proteins were electrotransferred to nitrocellulose membranes under standard conditions [70]. Membranes were blocked for 2 $\mathrm{h}$ in PBS containing 1\% casein, incubated overnight with the primary antibody diluted in the blocking solution, washed $3 \times 10 \mathrm{~min}$, and then incubated for $2 \mathrm{~h}$ at room temperature in secondary antibody conjugated to horseradish peroxidase (Dako $\mathrm{A} / \mathrm{S}$ ). A list of the primary and secondary antibodies and dilutions that were used is provided in Table 3.

\section{Authors' contributions}

MEM constructed and screened DNA libraries, prepared oligonucleotide probes, performed Southern blotting and Western blotting, participated in the analysis and interpretation of data, co-drafted and co-wrote the manuscript. THG led the conception and design of the study, codrafted and co-wrote the manuscript, performed DNA manipulations, participated in the analysis and interpretation of data, and annotated the sequences. DABD initiated the melioidosis studies, obtained bacterial isolates, assisted in the interpretation of data, and contributed to writing the manuscript. MLG assisted with the conception and design of the study, cultured bacterial isolates, performed DNA extraction, participated in the interpretation of data, and contributed to writing the manuscript. All authors read and approved the final manuscript.

\section{Additional material}

\begin{abstract}
Additional File 1
Antibody specificity. Methods for verifying antibody specificity; Construction and expression of recombinant fusion proteins; Characterisation of antibodies recognising MrgR and MrgS; Figure legends for Additional Figures

Click here for file

[http://www.biomedcentral.com/content/supplementary/14712180-6-70-S1.doc]
\end{abstract}

\section{Additional File 4}

Figure S3. Western blot showing the recognition of B. pseudomallei cellular components from 6 isolates by antibodies in convalescent sera pooled from 6 melioidosis patients.

Click here for file

[http://www.biomedcentral.com/content/supplementary/14712180-6-70-S4.eps]

\section{Additional File 2}

Figure S1. Western blot showing the recognition of MBP-MrgR fusion protein by affinity purified antibodies, anti-MrgR.

Click here for file

[http://www.biomedcentral.com/content/supplementary/14712180-6-70-S2.eps]

\section{Additional File 3}

Figure S2. Western blot showing the recognition of MBP-MrgS fusion protein by affinity purified antibodies, anti-MrgS.

Click here for file

[http://www.biomedcentral.com/content/supplementary/14712180-6-70-S3.eps]

\section{Acknowledgements}

This work was funded by the Egyptian government, through the Egyptian Education and Culture Bureau, London, UK. We thank Dr Ty Pitt, Centre for Infections, Health Protection Agency, Colindale, London for providing bacterial strains, Vanaporn Wuthiekanun, Wellcome Trust-Oxford University-Mahidol University Tropical Medicine Research Programme, Bangkok, Thailand, for providing convalescent sera from melioidosis patients, and Lynne Gay for technical assistance.

\section{References}

I. Jones AL, Beveridge TJ, Woods DE: Intracellular survival of Burkholderia pseudomallei. Infect Immun 1996, 64:782-790.

2. Pruksachartvuthi S, Aswapokee N, Thankerngpol K: Survival of Pseudomonas pseudomallei in human phagocytes. J Med Microbiol 1990, 31:109-114.

3. Cheng AC, Currie BJ: Melioidosis: epidemiology, pathophysiology and management. Clin Microb Rev 2005, 18:383-416.

4. Everett ED, Nelson RA: Pulmonary melioidosis. Observations in thirty-nine cases. Am Rev Resp Dis 1975, I I 2:331-340.

5. So SY, Chau PY, Leung YK, Lam WK, Yu DYC: Successful treatment of melioidosis caused by a multiresistant strain in an 
immunocompromised host with third generation cepharosporins. Am Rev Resp Dis 1983, I 27:650-654.

6. Dance DAB: Ecology of Burkholderia pseudomallei and the interactions between environmental Burkholderia spp. and human-animal hosts. Acta Trop 2000, 74:159-168.

7. Mitsuchi M, Wichaidlit $P$, Jeungnijnirund $S$ : Outlines of soils of the Northeastern Plateau, Thailand: Their characteristics and constraints. Japan International Cooperation Agency Report. Thailand: Siriphan Offset Pub. Co. Ltd; 1986.

8. Yabuuchi E, Wang L, Arakawa M, Yano I: Survival of Pseudomonas pseudomallei strains at $5^{\circ} \mathrm{C}$. Kansenshogaku Zasshi 1993, 67:33I-335

9. Ngauy V, Lemeshev Y, Sadkowski L, Crawford G: Cutaneous melioidosis in a man who was taken as a prisoner of war by the Japanese during World War II. J Clin Microbiol 2005, 43:970-972.

10. Dance DAB: Melioidosis. Curr Opin Infect Dis 2002, I 5:127-132.

II. Haase A, Janzen J, Barrett S, Currie B: Toxin production by Burkholderia pseudomallei strains and correlation with severity of melioidosis. J Med Microbiol 1997, 46:557-563.

12. Gauthier YP, Thibault FM, Paucod JC, Vidal DR: Protease production by Burkholderia pseudomallei and virulence in mice. Acto Trop 2000, 74:215-220.

13. Tuanyok A, Kim HS, Nierman WC, Yu Y, Dunbar J, Moore RA, Baker $P$, Tom M, Ling JML, Woods DE: Genome-wide expression analysis of iron regulation in Burkholderia pseudomallei and Burkholderia mallei using DNA microarrays. FEMS Microbiol Lett 2005, 252:327-335.

14. Korbsrisate S, Suwanasai N, Leelaporn A, Ezaki T, Kawamura Y, Asrasombath S: Cloning and characterization of a nonhemolytic phospholipase C gene from Burkholderia pseudomallei. J Clin Microbiol 1999, 37:3742-3745.

15. Nelson M, Prior JL, Lever MS, Jones HE, Atkins TP, Titball RW: Evaluation of lipopolysaccharide and capsular polysaccharide as subunit vaccines against experimental melioidosis. I Med Microbiol 2004, 53: I I77-1 I82.

16. Reckseidler SL, DeShazer D, Sokol PA, Woods DE: Detection of bacterial virulence genes by subtractive hybridization: Identification of capsular polysaccharide of Burkholderia pseudomallei as a major virulence determinant. Infect Immun 200 I, 69:34-44.

17. Reckseidler-Zenteno SL, DeVinney R, Woods DE: The capsular polysaccharide of Burkholderia pseudomallei contributes to survival in serum by reducing complement factor $\mathrm{C} 3 \mathrm{~b}$ deposition. Infect Immun 2005, 73: I 106-I I I5.

18. Stock AM, Robinson VL, Goudreau PN: Two-component signal transduction. Annu Rev Biochem 2000, 69:183-215.

19. Nessler S: The bacterial HPr kinase/phosphorylase: A new type of Ser/Thr kinase as antimicrobial target. Biochim Biophys Acta 2005, 1754:126-13|.

20. Stephenson K, Hoch JA: Developing inhibitors to selectively target two-component and phosphorelay signal transduction systems of pathogenic microorganisms. Curr Med Chem 2004, I I:765-773.

21. Calva E, Oropeza R: Two-component signal transduction systems, environmental signals and virulence. Microb Ecol 2000, 5I:I66-I76.

22. Galperin MY: Bacterial signal transduction network in a genomic perspective. Environ Microbiol 2004, 6:552-67.

23. Wolanin PM, Thomason PA, Stock JB: Histidine protein kinases: Key signal transducers outside the animal kingdom. Genome Biol 2002, 3:3013.1-3013.8.

24. Coote JG: Environmental sensing mechanisms in Bordetella. Adv Microb Physiol 200I, 44: |4I-8I.

25. Lucas RL, Lee CA: Unravelling the mysteries of virulence gene regulation in Salmonella typhimurium. Mol Microbiol 2000, 36:1024-33.

26. Bourret RB, Hess JF, Simon MI: Conserved aspartate residues and phosphorylation in signal transduction by the chemotaxis protein CheY. Proc Natl Acad Sci USA 1990, 87:41-45.

27. Forst $S$, Inouye M: Environmentally regulated gene expression for membrane proteins in Escherichia coli. Annu Rev Cell Biol 1988, 4:21-42

28. Jones AL, Deshazer D, Woods DE: Identification and characterization of a two-component regulatory system involved in invasion of eukaryotic cells and heavy-metal resistance in Burkholderia pseudomallei. Infect Immun 1997, 65:4972-4977.

29. Majdalani N, Gottesman S: The Rcs phosphorelay: A complex signal transduction system. Annu Rev Microbiol 2005, 59:379-405.

30. Stock JB, Surette MG, Levit M, Stock AM: Two-component signal transduction system: structure-function relationships and mechanisms of catalysis. In Two-Component Signal Transduction Edited by: Hoch JA, Silhavy TJ. Washington DC: ASM Press; 1995:25-32.

31. Mizuno T: Compilation of all genes encoding two-component phosphotransfer signal transducers in the genome of Escherichia coli. DNA Res 1997, 4:16I-168.

32. Holden MTG, Titball RW, Peacock SJ, Cerdeno-Tarraga AM, Atkins T, Crossman LC, Pitt T, Churcher C, Mungall K, Bentley SD, Sebaihia M, Thomson NR, Bason N, Beacham IR, Brooks K, Brown KA, Brown NF, Challis GL, Cherevach I, Chillingworth T, Cronin A, Crossett B, Davis P, DeShazer D, Feltwell T, Fraser A, Hance Z, Hauser $\mathrm{H}, \mathrm{Hol}-$ royd $S$, Jagels K, Keith KE, Maddison M, Moule S, Price C, Quail MA, Rabbinowitsch E, Rutherford K, Sanders M, Simmonds M, Songsivilai S, Stevens K, Tumapa S, Vesaratchavest M, Whitehead S, Yeats C, Barrell BG, Oyston PCF, Parkhill J: Genomic plasticity of the causative agent of melioidosis, Burkholderia pseudomallei. Proc Natl Acad Sci USA 2004, I0 I: | $4240-14245$

33. Kim HS, Schell MA, Yu Y, Ulrich RL, Sarria SH, Nierman WC, DeShazer D: Bacterial genome adaptation to niches: Divergence of the potential virulence genes in three Burkholderia species of different survival strategies. BMC Genomics 2005, 6:174.

34. Ong C, Ooi CH, Wang D, Chong $\mathrm{H}, \mathrm{Ng} \mathrm{KC}$, Rodrigues $\mathrm{F}$, Lee MA, Tan $P$ : Patterns of large-scale genomic variation in virulent and avirulent Burkholderia species. Genome Res 2004, 14:2295-2307.

35. Dejsirilert S, Kondo E, Chiewsilp D, Kanai K: Growth and survival of Pseudomonas pseudomallei in acidic environments. Jpn J Med Sci Biol 1991, 44:63-74.

36. Yabuuchi E, Miyajima N, Hotta H, Ohyama A, Tanaka N: Pseudomonas cepacia from blood of a burn patient. Med J Osaka Univ 1970, 2 I: I-6.

37. Lajudie P, Brygoo ER: Contribution a l'etude du pouvoir pathogene du bacille de Whitmore. Ann Instit Pasteur 1953, 85:99-106.

38. Vesselinova A, Najdenski H, Nikolova S, Kussovski V: Experimental melioidosis in hens. Zentralbl Veterinarmed B 1996, 43:37I-378.

39. Schmidt AJ, Ryjenkov DA, Gomelsky M: The ubiquitous protein domain EAL is a cyclic diguanylate-specific phosphodiesterase: Enzymatically active and inactive EAL domains. J Bacteriol 2005, 187:4774-478।.

40. Matoo S, Foreman-Wykert AK, Cotter PA, Miller JF: Mechanisms of Bordetella pathogenesis. Front Biosci 200I, 6:EI68-EI86.

41. Boucher L, Ouzounis CA, Enright AJ, Blencowe BJ: A genome-wide survey of RS domain proteins. RNA 200I, 7:1693-1701.

42. Derewenda ZS, Cambillau C: Effects of gene mutations in lipoprotein and hepatic lipases as interpreted by a molecular model of the pancreatic lipase. I Biol Chem 1991, 266:23||2-23|19.

43. Pallen MJ, Chaudhuri RR, Henderson IR: Genomic analysis of secretion systems. Curr Opin Microbiol 2003, 6:519-527.

44. Bendtsen JD, Kiemer L, Fausbøll A, Brunak S: Non-classical protein secretion in bacteria. BMC Microbiol 2005, 5:58.

45. Yabuuchi E, Kosako Y, Oyaizu H, Yano I, Hotta H, Hashimoto Y, Ezaki T, Arakawa M: Proposal of Burkholderia gen. nov. and transfer of seven species of the genus Pseudomonas homology group II to the new genus, with the type species Burkholderia cepacia (Palleroni and Holmes I 98I) comb. nov. Microbiol Immunol 1992, 36:125I-1275.

46. Wuthiekanun V, Smith MD, Dance DA, Walsh AL, Pitt TL, White NJ: Biochemical characteristics of clinical and environmental isolates of Burkholderia pseudomallei. J Med Microbiol 1996, 45:408-4I2.

47. La Camera S, Geoffroy P, Samaha H, Ndiaye A, Rahim G, Legrand M, Heitz T: A pathogen-inducible patatin-like lipid acyl hydrolase facilitates fungal and bacterial host colonization in Arabidopsis. Plant J 2005, 44:8I 0-825

48. Hirose Y, Kariya K, Nakanishi Y, Kurono Y, Achiwa K: Inversion of enantioselectivity in hydrolysis of I,4-dihydropyridines by point mutation of lipase PS. Tetrahedron Lett 1995, 36: I 063- 1066. 
49. Winstanley C, Hales BA, Hart CA: Evidence for the presence in Burkholderia pseudomallei of a type III secretion system-associated gene cluster. J Med Microbiol 1999, 48:649-656.

50. Attree O, Attree I: A second type III secretion system in Burkholderia pseudomallei : who is the real culprit? Microbiology 200I, I47:3197-3199.

5I. Rainbow L, Hart CA, Winstanley C: Distribution of type III secretion gene clusters in Burkholderia pseudomallei, B. thailandensis and B. mallei. J Med Microbiol 2002, 5 I:374-384

52. Godoy D, Randle G, Simpson AJ, Aanensen DM, Pitt TL, Kinoshita R, Spratt BG: Multilocus sequence typing and evolutionary relationships among the causative agents of melioidosis and glanders, Burkholderia pseudomallei and Burkholderia mallei. J Clin Microbiol 2003, 4 I :2068-2079.

53. Gee JE, Sacchi CT, Glass MB, De BK, Weyant RS, Levett PN, Whitney AM, Hoffmaster AR, Popovic T: Use of I 6S rRNA gene sequencing for rapid identification and differentiation of Burkholderia pseudomallei and B. mallei. J Clin Microbiol 2003, 4I:4647-4654.

54. Haase A, Vaughan HS, Melder A, Wood Y, Janmaat A, Gilfedder J, Kemp D, Currie B: Subdivision of Burkholderia pseudomallei ribotypes into multiple types by random amplified polymorphic DNA analysis provides new insights into epidemiology. I Clin Microbiol 1995, 33: I687-1690.

55. Cohan FM: Genetic exchange and evolutionary divergence in prokaryotes. Trends Ecol Evol 1994, 9: I75-180.

56. Winstanley C, Hales BA, Corkill JE, Gallagher MJ, Hart CA: Flagellin gene variation between clinical and environmental isolates of Burkholderia pseudomallei contrasts with the invariance among clinical isolates. J Med Microbiol 1998, 47:689-694.

57. Meyers LA, Levin BR, Richardson AR, Stojiljkovic I: Epidemiology, hypermutation, within-host evolution and the virulence of Neisseria meningitidis. Proc R Soc Lond B 2003, 270:1667-1677.

58. Jolley KA, Wilson DJ, Kriz P, Mcvean G, Maiden MCJ: The influence of mutation, recombination, population history, and selection on patterns of genetic diversity in Neisseria meningitidis. Mol Biol Evol 2005, 22:562-569.

59. Pitt TL, Trakulsomboon S, Dance DAB: Molecular phylogeny of Burkholderia pseudomallei. Acta Trop 2000, 74: I8I-185.

60. Inglis TJ, Rigby JP, Robertson TA, Dutton NS, Henderson M, Chang B]: Interaction between Burkholderia pseudomallei and Acanthamoeba species results in coiling phagocytosis, endamebic bacterial survival, and escape. Infect Immun 2000, 68: I68I-I686.

6I. Levy A, Chang BJ, Abbott LK, Kuo J, Harnett G, Inglis TJ): Invasion of spores of the arbuscular mycorrhizal fungus Gigaspora decipiens by Burkholderia spp. Appl Environ Microbiol 2003, 69:6250-6256.

62. Dance $D A B$, Wuthiekanun $V$, Naigowit $P$, White $N$ J: Identification of Pseudomonas pseudomallei in clinical practice: use of simple screening tests and API20NE. J Clin Pathol 1989, 42:645-648.

63. Sambrook J, Fritsch EF, Maniatis T: Molecular cloning: A laboratory manual. 2nd edition. New York: Cold Spring Habor Laboratory Press.

64. Berkeley Drosophila Genome Project [http://www.fruitfly.org/ seq tools/promoter.html]

65. National Centre for Biotechnology Information [http:// www.ncbi.nlm.nih.gov/]

66. ExPASy Proteomics Server [http://www.expasy.ch/]

67. Institut Pasteur [http://www.pasteur.fr/english.html]

68. MultAlin [http://prodes.toulouse.inra.fr/multalin/multalin.html]

69. SecretomeP 2.0 server [http://www.cbs.dtu.dk/services/Secre tomeP/]

70. Towbin HM, Staehelin T, Gordon J: Electrophoretic transfer of proteins from polyacrylamide gels to nitrocellulose sheets: procedure and some applications. Proc Natl Acad Sci USA 1979. 76:4350-4354

\section{Publish with Bio Med Central and every} scientist can read your work free of charge

"BioMed Central will be the most significant development for disseminating the results of biomedical research in our lifetime. "

Sir Paul Nurse, Cancer Research UK

Your research papers will be:

- available free of charge to the entire biomedical community

- peer reviewed and published immediately upon acceptance

- cited in PubMed and archived on PubMed Central

- yours - you keep the copyright

Submit your manuscript here:

http://www.biomedcentral.com/info/publishing_adv.asp
BioMedcentral 